\title{
Influence of Magnetite Nanoparticles Shape and Spontaneous Surface Oxidation on the Electron Transport Mechanism
}

\author{
Adrian Radoń ${ }^{1,2, *(\mathbb{D}}$, Mariola Kądziołka-Gaweł ${ }^{3} \mathbb{D}$, Dariusz Lukowiec $^{2} \mathbb{D}$, Piotr Gębara ${ }^{4} \mathbb{D}$, \\ Katarzyna Cesarz-Andraczke ${ }^{2} \mathbb{D}$, Aleksandra Kolano-Burian ${ }^{1}$, Patryk Włodarczyk ${ }^{1}$, Marcin Polak ${ }^{1}$ \\ and Rafał Babilas 2 (D)
}

check for updates

Citation: Radon, A.; KądziołkaGawel, M.; Łukowiec, D.; Gębara, P.; Cesarz-Andraczke, K.; Kolano-Burian, A.; Włodarczyk, P.; Polak, M.; Babilas, R. Influence of Magnetite Nanoparticles Shape and Spontaneous Surface Oxidation on the Electron Transport Mechanism. Materials 2021, 14, 5241. https://doi.org/10.3390/ma14185241

Academic Editor: Georgios C. Psarras

Received: 12 August 2021

Accepted: 8 September 2021

Published: 12 September 2021

Publisher's Note: MDPI stays neutral with regard to jurisdictional claims in published maps and institutional affiliations.

Copyright: (c) 2021 by the authors. Licensee MDPI, Basel, Switzerland. This article is an open access article distributed under the terms and conditions of the Creative Commons Attribution (CC BY) license (https:/ / creativecommons.org/licenses/by/ $4.0 /)$.
1 Łukasiewicz Research Network-Institute of Non-Ferrous Metals, Sowinskiego 5 St., 44-100 Gliwice, Poland; aleksandra.kolano-burian@imn.gliwice.pl (A.K.-B.); patryk.wlodarczyk@imn.gliwice.pl (P.W.); marcin.polak@imn.gliwice.pl (M.P.)

2 Faculty of Mechanical Engineering, Silesian University of Technology, Konarskiego 18 a St., 44-100 Gliwice, Poland; dariusz.lukowiec@polsl.pl (D.Ł.); katarzyna.cesarz-andraczke@polsl.pl (K.C.-A.); rafal.babilas@polsl.pl (R.B.)

3 A. Chelkowski Institute of Physics, University of Silesia, 75 Pułku Piechoty 1A St., 41-500 Chorzów, Poland; mariola.kadziolka-gawel@us.edu.pl

4 Institute of Physics, Czestochowa University of Technology, al. Armii Krajowej 19, 42-200 Czestochowa, Poland; gebara.piotr@wip.pcz.pl

* Correspondence: adrianr@imn.gliwice.pl

Abstract: The spontaneous oxidation of a magnetite surface and shape design are major aspects of synthesizing various nanostructures with unique magnetic and electrical properties, catalytic activity, and biocompatibility. In this article, the roles of different organic modifiers on the shape and formation of an oxidized layer composed of maghemite were discussed and described in the context of magnetic and electrical properties. It was confirmed that $\mathrm{Fe}_{3} \mathrm{O}_{4}$ nanoparticles synthesized in the presence of triphenylphosphine could be characterized by cuboidal shape, a relatively low average particle size $(9.6 \pm 2.0 \mathrm{~nm})$, and high saturation magnetization equal to $55.2 \mathrm{emu} / \mathrm{g}$. Furthermore, it has been confirmed that low-frequency conductivity and dielectric properties are related to surface disordering and oxidation. The electric energy storage possibility increased for nanoparticles with a disordered and oxidized surface, whereas the dielectric losses in these particles were strongly related to their size. The cuboidal magnetite nanoparticles synthesized in the presence of triphenylphosphine had an ultrahigh electrical conductivity $\left(1.02 \times 10^{-4} \mathrm{~S} / \mathrm{cm}\right.$ at $\left.10 \mathrm{~Hz}\right)$ in comparison to the spherical ones. At higher temperatures, the maghemite content altered the behavior of electrons. The electrical conductivity can be described by correlated barrier hopping or overlapping large polaron tunneling. Interestingly, the activation energies of electrons transport by the surface were similar for all the analyzed nanoparticles in low- and high-temperature ranges.

Keywords: magnetite; maghemite; electrical conductivity; surface oxidation

\section{Introduction}

The modification of the surface of nanoparticles (NPs) plays an essential role in the synthesis of materials with controlled properties. The formation of functionalized nanoparticles with core-shell nanostructures are widely studied, especially in medical and catalytic applications [1-4]. This procedure allows one to change the properties of nanoparticles, especially to increase their reactivity, stability, and even biocompatibility. For many different nanostructures, the formation of particles with a core-shell structure results in highly efficient gas sensors synthesis. For example, Au@NiO nanoparticles are much more sensitive to ethanol than pristine $\mathrm{NiO}$, which is related to the effect of the electronic and chemical sensitization of $\mathrm{Au}$ [5]. The synergetic effects of two different oxides on acetone sensitivity are also observed in systems such as $\mathrm{Fe}_{3} \mathrm{O}_{4} @ \mathrm{Co}_{3} \mathrm{O}_{4}$ and are associated with the formation of the heterojunction [6]. In addition, the core-shell 
combination of nanoparticles and the functionalization process can be used to prepare materials with high catalytic activity. Sappino et al. [7] demonstrated that $\mathrm{Fe}_{3} \mathrm{O}_{4} @ \mathrm{SiO}_{2}$ nanoparticles with a core-shell structure could be successfully functionalized to obtain stable and removable amino alcohol catalysts that can be used for the asymmetric addition of diethylzinc to aromatic aldehydes. The functionalization of $\mathrm{Fe}_{3} \mathrm{O}_{4} @ \mathrm{SiO}_{2}$ nanoparticles has also been successfully used to prepare nanocatalysts functionalized by alkylsulfonic and butylcaboxylic acids, which were used by Ingle et al. for the production of biofuels from sugarcane straw [8].

On the other hand, magnetite nanoparticles functionalized with polymers, such as polylactic acid, cyclodextrins, amine-terminated poly(propylene glycol), and polyethylene glycol, can be used as magnetic resonance imaging agents and efficient drug delivery systems $[9,10]$. Therefore, understanding the functionalization mechanisms and the influence of surface modification on the properties of magnetite nanoparticles is essential in various fields of research. Recently, the role of the dissolution of the surface of oxidized magnetite nanoparticles in catalytic activity and magnetoelectric properties was discussed [11]. It has been shown that chemical treatment of magnetite nanoparticles synthesized by the co-precipitation method with malonic acid results in surface reorganization, dissolution of the oxidized layer, and spontaneous functionalization with an organic acid. Moreover, this process reduces the catalytic activity and increases the electrical conductivity of these nanoparticles 10 times.

The oxidation of magnetite to maghemite can occur spontaneously, or it can take place under certain conditions. This process can occur even during the synthesis; therefore, the synthesis should be carried out in anaerobic conditions [12]. The oxidation of a magnetite surface results in phase transformation, in which magnetite is transformed into maghemite [13]. In the magnetite structure, the tetrahedral sites (A-sites) are occupied by $\mathrm{Fe}^{3+}$ ions and the octahedral sites (B-sites) are occupied by $\mathrm{Fe}^{3+}$ and $\mathrm{Fe}^{2+}$ ions, whereas in maghemite, all $\mathrm{Fe}^{2+}$ ions convert into $\mathrm{Fe}^{3+}$ ions with the formation of iron vacancies (2.5 per $21.5 \mathrm{Fe}^{3+}$ ions in the unit cell) as a result of $\mathrm{Fe}_{3} \mathrm{O}_{4}$ NPs oxidation $[4,14]$. The magnetic response under AC-fields of magnetite and maghemite nanoparticles of the same size is also different, which has been confirmed by Morales et al. [15]. Therefore, even though both iron oxides exhibit ferrimagnetic properties at room temperature, their electronic properties must be different, which should be related to the changes in electron transport. The electrical properties of pure magnetite nanoparticles have been discussed and described in detail in the previous work [16]. In the pure $\mathrm{Fe}_{3} \mathrm{O}_{4}$ phase, two different models were used to describe the behaviors of electrons at different temperatures and frequency ranges.

Moreover, it was confirmed that the energy of tunneling of small polarons decreases with increasing temperature, and for the high-temperature regions, it may occur spontaneously. Interestingly, the electron behavior in magnetite is strongly related to the structure, and even Drude-like behavior can be observed for this type of material [17]. The Drude model uses the kinetic theory of gases to explain electrons' movement in, for example, metals and heavy fermionic materials [18]. Above that, the changes in dielectric properties have been observed for various mixed ferrites such as barium ferrite-zinc ferrite and $\mathrm{Sr}_{2} \mathrm{Cu}_{2} \mathrm{Fe}_{12} \mathrm{O}_{22}$-zinc ferrite systems, which indicates that the presence of other structures can drastically change the behavior of electrons in this type of material $[19,20]$.

Despite that, there is a lack of knowledge of how the surface modification can change magnetic and dielectric properties of magnetite nanoparticles, especially charge carriers motions and electric energy storage properties. Those, in turn, may contribute to the development of highly sensitive and stable toxic gas sensors [21]. Therefore, this study investigated the influence of magnetite crystallization on spherical and cuboidal nanoparticles and the disordered and oxidized magnetite surface on the behavior of electrons in magnetite nanoparticles. Oxidized magnetite nanoparticles with various $\gamma-\mathrm{Fe}_{2} \mathrm{O}_{3}$ contents and cuboidal shapes were synthesized by the controlled co-precipitation method, and the maghemite presence was determined by Mössbauer spectroscopy. The mechanism of 
electrical conductivity in magnetite with different shapes as well as surface disordering and oxidation was proposed and discussed.

\section{Materials and Methods}

\subsection{Synthesis of Magnetite Nanoparticles in a Hydrophobic-Hydrophilic Environment}

The synthesis of magnetite nanoparticles was performed in a hydrophobic-hydrophilic environment, in which the upper layer was hexadecane, protecting the formed nanoparticles against contact with atmospheric oxygen. First, $20 \mathrm{mmol}$ of $\mathrm{FeCl}_{3}$ (anhydrous) and $10 \mathrm{mmol}$ of $\mathrm{FeSO}_{4} \cdot 7 \mathrm{H}_{2} \mathrm{O}$ were dissolved in a stock solution with $50 \mathrm{~mL}$ of water and $50 \mathrm{~mL}$ of hexadecane, respectively. Then, $5 \mathrm{mmol}$ of an organic modifier, i.e., ethylenediamine (en), chloramine $\mathrm{T}(\mathrm{ClT})$, or triphenylphosphine $\left(\mathrm{PPh}_{3}\right)$, was added to the as-prepared solution with constant stirring. It was observed that the $\mathrm{PPh}_{3}$ was dissolved only in the hexadecane layer due to its low solubility in water. Next, the solution was heated up to $328 \mathrm{~K}$ in an ultrasonic water bath during a continuous sonication process. Finally, a solution with $80 \mathrm{~mL}$ of water and $200 \mathrm{mmol}$ of $\mathrm{NaOH}$ was added dropwise to the reaction mixture. The black precipitate was sonicated in a post-reaction solution throughout the process. The powder was collected by filtration, washed twice with water, ethanol, and acetone and then dried at $333 \mathrm{~K}$ for $2 \mathrm{~h}$. The obtained samples were marked as $\mathrm{Fe}_{3} \mathrm{O}_{4}$-en NPs, $\mathrm{Fe}_{3} \mathrm{O}_{4}-\mathrm{ClT} \mathrm{NPs}$, and $\mathrm{Fe}_{3} \mathrm{O}_{4}-\mathrm{PPh}_{3} \mathrm{NPs}$, depending on the modifier used for the synthesis. The same synthesis method was used to prepare $\mathrm{Fe}_{3} \mathrm{O}_{4} \mathrm{NPs}$ without using any additional organic modifier.

\subsection{Materials Characterization}

The phase purity and crystal structure of the synthesized nanoparticles were described by X-ray diffraction (XRD). The diffractograms were collected using a Rigaku MiniFlex 600 with a copper tube $\mathrm{Cu} \mathrm{K} \alpha(\lambda=0.15406 \mathrm{~nm})$ and a D/teX Ultra silicon strip detector (Rigaku Corporation, Tokyo, Japan). The tube voltage was $40 \mathrm{kV}$, and the current was $15 \mathrm{~mA}$. The measurements were performed with a step width of $0.02^{\circ}$ in the scan range from $10^{\circ}$ to $90^{\circ}$. The phase analysis was performed using a dedicated Rigaku PDXL software suite. Fourier-transform infrared (FTIR) spectroscopy was used to determine the presence of organic modifiers on the surface of magnetite nanoparticles and confirm the presence of maghemite on their surface. FTIR spectra were recorded in the infrared transmission mode with a range of $4000-400 \mathrm{~cm}^{-1}$ using a Nicolet $6700 / 8700$ FTIR spectrometer (Thermo Fisher Scientific, Waltham, MA, USA) and the KBr pellet method. The transmission electron microscope (TEM) micrographs of the magnetite nanoparticles deposited on the surface of a copper grid with a carbon film were collected using S/TEM TITAN 80-300 (FEI Company, Eindhoven, The Netherlands). The average nanoparticles size $\left(D_{a v}\right)$ was calculated based on the analysis of TEM micrographs. For this purpose, the size of nanoparticles was measured for at least 100 different particles and at least 5 different micrographs. The $D_{a v}$ value was calculated as a mean value. The magnetic properties of magnetite nanoparticles were determined by a Quantum Design VersaLab (Quantum Design, San Diego, CA, USA) cryogen-free vibrating-sample magnetometer (VSM). To determine the presence of an oxidized surface and to confirm the existence of the magnetite structure, the ${ }^{57} \mathrm{Fe}$ Mössbauer spectra (MS) were recorded using the MS96 spectrometer (Tampa, FL, USA) with a ${ }^{7} \mathrm{Co}: \mathrm{Rh}$ source (activity $\sim 25 \mathrm{mCi}$ ), the linear arrangement of the ${ }^{57} \mathrm{Co}$ source, absorber and detector and a multichannel analyzer with 1024 channels. A metallic $\alpha$-Fe foil absorber was used to calibrate velocity and isomer shift. Spectral analysis was performed using WMOSS software (Ion Prisecaru, WMOSS4 Mössbauer Spectral Analysis Software, 2009-2016). Measurements of dielectric spectra (complex permittivity and dielectric losses) and electrical conductivity were performed for compressed samples in the form of discs with a uniform diameter of $10 \mathrm{~mm}$ at a compression pressure of 30 bar. Measurements were performed using a Concept 81 dielectric spectrometer equipped with a Novo-cool temperature control system and an Alpha analyzer (Novocontrol, Montabaur, Germany) in 
the frequency range from 0.01 to $10 \mathrm{MHz}$ and in the temperature range of $173-363 \mathrm{~K}$ with $\Delta \mathrm{T}$ equal to $10 \mathrm{~K}$.

\section{Results and Discussion}

\subsection{Structural Analysis and Magnetic Properties of Magnetite Nanoparticles}

The XRD patterns recorded for synthesized magnetite nanoparticles using various organic modifiers are shown in Figure 1a. As one can see, all patterns can be very well described using Miller indices characteristic to the magnetite phase (Fd-3m; $a=b=c=0.8375 \mathrm{~nm} ; \alpha=\beta=\gamma=90^{\circ}$ ). Based on the measured XRD patterns, average crystallite size and intrinsic strain were calculated using the Halder-Wagner method, which was previously used to determine the size of crystallites of magnetite and other ferrites [22-24]. Intrinsic strain in nanomaterials is prevalent and can be determined by analyzing the broadening of diffraction peaks. This broadening in nanomaterials is related to the fine size and the existence of strain, which is related to the high concentration of defects such as dislocations, point defects, stacking faults, and grain boundaries [25]. Therefore, strain analysis can provide helpful information on the defects concentration in magnetite nanoparticles. The results of the analysis are presented in Table 1. As can be seen, the use of chloramine $\mathrm{T}$ and ethylenediamine resulted in the synthesis of nanoparticles with an average crystallite size $\left(D_{H-W}\right)$ equal to or greater than $10 \mathrm{~nm}$, while the lowest $D_{H-W}$ value equal to $8.04 \mathrm{~nm}$ was found for nanoparticles synthesized with the use of $\mathrm{PPh}_{3}$. Interestingly, the analysis of intrinsic strain showed that the highest $\varepsilon$ value was obtained for nanoparticles synthesized with $\mathrm{PPh}_{3}$ and the lowest value (undetectable) was achieved for nanoparticles synthesized without organic modifiers. The presence of the strain in nanoparticles can be related to the numerous factors such as ultrafine size, different shapes, highly disordered surface, and presence of vacancies [26,27]. To understand these changes in $D_{H-W}$ and $\varepsilon$, the analyses of the FTIR spectra (presented in Figure $1 \mathrm{~b}$ ) and the TEM images (presented in Figure 2) were performed.
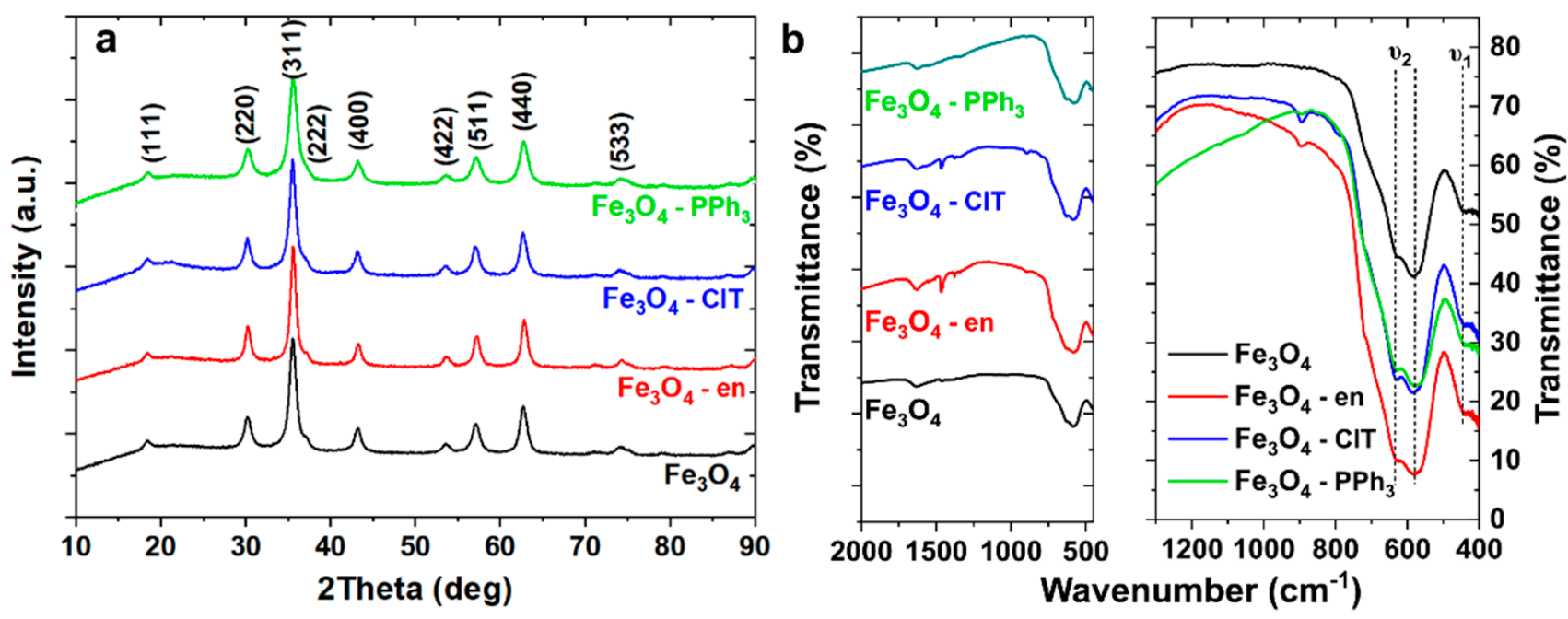

Figure 1. Structural analysis of magnetite nanoparticles: (a) X-ray diffraction patterns of magnetite nanoparticles synthesized without $\left(\mathrm{Fe}_{3} \mathrm{O}_{4}\right)$ and with the presence of ethylenediamine $\left(\mathrm{Fe}_{3} \mathrm{O}_{4}-\mathrm{en}\right)$, chloramine $\mathrm{T}\left(\mathrm{Fe}_{3} \mathrm{O}_{4}-\mathrm{ClT}\right)$, and triphenylphosphine $\left(\mathrm{Fe}_{3} \mathrm{O}_{4}-\mathrm{PPh}_{3}\right)$; (b) Fourier-transform infrared spectra of the same samples. The left panel presents the spectra in a wide frequency range, and the right panel shows the spectra in a narrow frequency range, in which characteristic vibrations from Fe-O bonds $\left(v_{1}\right.$ and $\left.v_{2}\right)$ occurred. 
Table 1. The average crystallite size $\left(D_{H-W}\right)$, intrinsic strain $(\varepsilon)$, average particle size $\left(D_{a v}\right)$, and characteristic for Fe-O bonds vibrations $\left(v_{1}, v_{2}\right.$, and $\left.v_{2^{\prime}}\right)$.

\begin{tabular}{ccccccc}
\hline Sample & $\boldsymbol{D}_{\boldsymbol{H}-\boldsymbol{W}}(\mathbf{n m})$ & $\boldsymbol{\varepsilon}\left(\mathbf{1 0}^{-\mathbf{3}}\right)$ & $\boldsymbol{D}_{\boldsymbol{a v}}(\mathbf{n m})$ & $\boldsymbol{v}_{\mathbf{1}}\left(\mathbf{c m}^{-\mathbf{1}}\right)$ & $\boldsymbol{v}_{\mathbf{2}}\left(\mathbf{c m}^{-\mathbf{1}}\right)$ & $\boldsymbol{v}_{\mathbf{2}^{\prime}}\left(\mathbf{c m}^{-\mathbf{1}}\right)$ \\
\hline $\mathrm{Fe}_{3} \mathrm{O}_{4}$ & 9.06 & 0 & $11.1 \pm 2.2$ & 444.5 & 583.6 & 630.0 \\
$\mathrm{Fe}_{3} \mathrm{O}_{4}-\mathrm{en}$ & 11.8 & 14.6 & $10.7 \pm 3.8$ & 445.5 & 582.4 & 629.6 \\
$\mathrm{Fe}_{3} \mathrm{O}_{4}-\mathrm{ClT}$ & 10 & 13.11 & $11.4 \pm 2.6$ & 444.5 & 588.0 & 631.6 \\
$\mathrm{Fe}_{3} \mathrm{O}_{4}-\mathrm{PPh}_{3}$ & 8.04 & 21.7 & $9.6 \pm 2.0$ & 440.6 & 580.5 & 630.6 \\
\hline
\end{tabular}

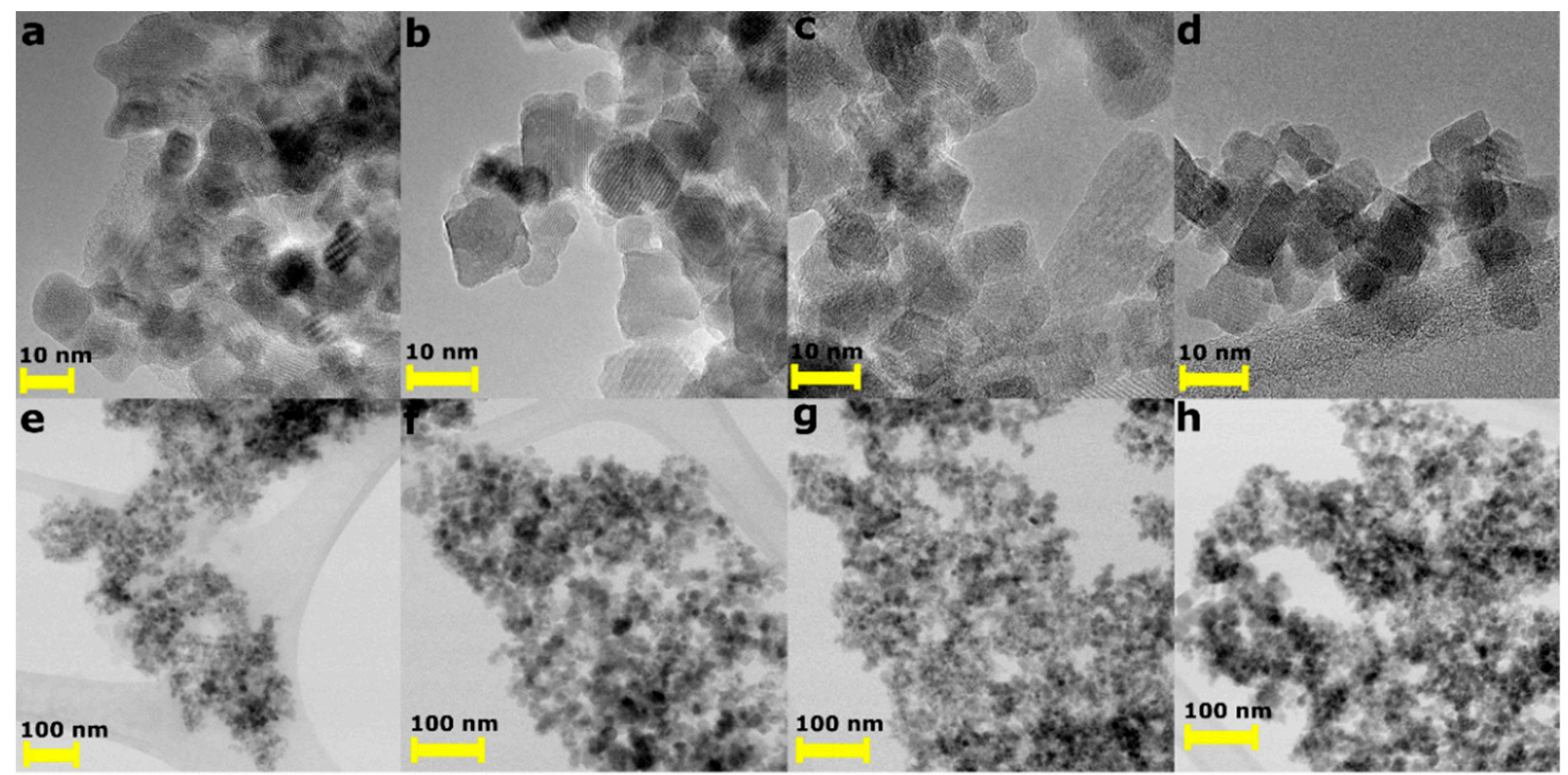

Figure 2. Transmission electron microscopy images of magnetite nanoparticles synthesized without (a,e) and with the presence of en $(\mathbf{b}, \mathbf{f}), \mathrm{ClT}(\mathbf{c}, \mathbf{g})$, and $\mathrm{PPh}_{3}(\mathbf{d}, \mathbf{h})$.

The FTIR spectra over a wide range of wavenumbers (left panel in Figure 1b) confirmed that $\mathrm{Fe}_{3} \mathrm{O}_{4} \mathrm{NPs}$ and $\mathrm{Fe}_{3} \mathrm{O}_{4}-\mathrm{PPh}_{3} \mathrm{NPs}$ were pure in the context of the presence of hexadecane and $\mathrm{PPh}_{3}$. Accordingly, $\mathrm{PPh}_{3}$ molecules only changed the average crystallite size and intrinsic strain in the synthesis step by interacting with the crystallized nanoparticles without spontaneously functionalizing them. In the case of $\mathrm{Fe}_{3} \mathrm{O}_{4}$-en NPs and $\mathrm{Fe}_{3} \mathrm{O}_{4}-\mathrm{ClT}$ NPs, the presence of $\mathrm{C}-\mathrm{H}$ bonds was confirmed in the FTIR spectra. Therefore, both organic modifiers changed the structure and morphology of nanoparticles and functionalize their surface. Probably negatively charged molecules interacted with iron ions and could not be removed even when washing samples [28]. The narrow range of wavenumbers (right panel in Figure 1b) showed the two characteristic vibrations of Fe-O bonds (marked as $v_{1}$ and $v_{2}$ ). These vibrations are also listed in Table 1. For bulk magnetite, the $v_{1}$ vibrations occurred at much lower wavenumbers (about $375 \mathrm{~cm}^{-1}$ ); however, for nanoparticles, peak shifts to higher wavenumbers can occur, which is related to the fine size of the particles [29]. The dual nature of the $v_{2}$ is related to the oxidized surface in which maghemite is formed. For this phase, vibrational mode with the $\mathrm{T}_{2}$ symmetry occurs, whereas only one vibration mode with $\mathrm{T}_{1 \mathrm{u}}$ symmetry at $\pm 600 \mathrm{~cm}^{-1}$ can be observed for pure magnetite nanoparticles [30].

The analysis of TEM images confirmed that all nanoparticles had an ultrafine size; however, their size distribution was broad ( $D_{a v}$ in Table 1). This is characteristic of magnetite nanoparticles synthesized by the co-precipitation method. In this method, it is challenging to control the growth of $\mathrm{Fe}_{3} \mathrm{O}_{4}$ and synthesize uniform monodisperse nanoparticles. Moreover, as shown in Figure 2, all nanoparticles were strongly agglomerated, and 
only the $\mathrm{Fe}_{3} \mathrm{O}_{4}$ NPs had a near-spherical shape. Other samples crystallized into cuboidal forms. Moreover, their surface was strongly disordered, which is consistent with the measurements of intrinsic strain. For the $\mathrm{Fe}_{3} \mathrm{O}_{4}$-en and $\mathrm{Fe}_{3} \mathrm{O}_{4}-\mathrm{PPh}_{3}$ nanoparticles, $\varepsilon$ was the highest, and after analysis of the TEM micrographs, it can be connected primarily with the highly disordered surface.

As presented above, the structural analysis clearly showed that the average crystallite size, shape, and surface functionalization were different for all synthesized samples. Therefore, their magnetic properties should be different. Interestingly, the $D_{H-W}$ values were similar for all samples (between 8.04 and $11.8 \mathrm{~nm}$ ). Therefore, the changes in magnetic behavior could be related mainly to differences in the surface of nanoparticles. The recorded VSM curves are shown in Figure 3, and the parameters obtained from the curves, i.e., saturation magnetization $\left(M_{s}\right)$, remanence $\left(M_{r}\right)$, coercivity $\left(H_{c}\right)$, and $M_{r} / M_{s}$ ratio, are summarized in Table 2. It can be noticed that $\mathrm{Fe}_{3} \mathrm{O}_{4} \mathrm{NPs}$ and $\mathrm{Fe}_{3} \mathrm{O}_{4}-\mathrm{PPh}_{3} \mathrm{NPs}$ had similar magnetic properties, especially the $M_{s}$ value. For nanoparticles synthesized using $\mathrm{PPh}_{3}$, the $M_{r}$ and $H_{c}$ values were lower than for nanoparticles synthesized without organic modifiers, which confirmed that $\mathrm{PPh}_{3}$ plays a crucial role in synthesizing $\mathrm{Fe}_{3} \mathrm{O}_{4} \mathrm{NPs}$ with good superparamagnetic properties. Lower $M_{S}$ values were recorded for nanoparticles synthesized in the presence of $\mathrm{ClT}$ and en. For $\mathrm{Fe}_{3} \mathrm{O}_{4}-\mathrm{ClT}$ NPs, $\mathrm{H}_{c}$ was much slower than for $\mathrm{Fe}_{3} \mathrm{O}_{4}$-en NPs, but the $M_{s}$ value was only $44.75 \mathrm{emu} / \mathrm{g}$, which is probably related to the presence of a highly oxidized surface.

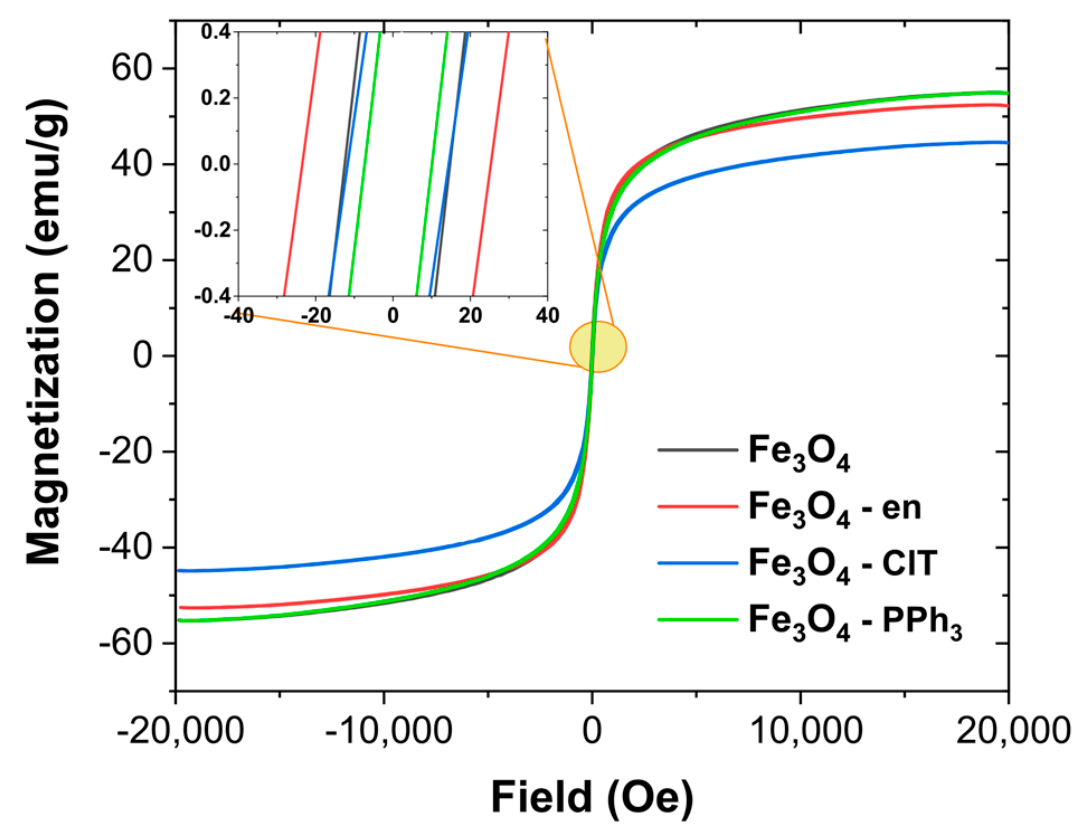

Figure 3. Magnetization curves obtained by a vibrating-sample magnetometer. The inset shows the enlarged area near the coercive field.

Table 2. Magnetic properties of $\mathrm{Fe}_{3} \mathrm{O}_{4} \mathrm{NPs}$ (saturation magnetization $\left(M_{s}\right)$, remanence $\left(M_{r}\right)$, coercivity $\left(H_{c}\right)$, and $M_{r} / M_{s}$ ratio).

\begin{tabular}{ccccc}
\hline Sample & $\boldsymbol{M}_{\boldsymbol{s}}(\mathbf{e m u} / \mathbf{g})$ & $\boldsymbol{M}_{\boldsymbol{r}}(\mathbf{e m u} / \mathbf{g})$ & $\boldsymbol{H}_{\boldsymbol{c}}(\mathbf{O e})$ & $\boldsymbol{M}_{\boldsymbol{r}} / \boldsymbol{M}_{\boldsymbol{s}}$ (a.u.) \\
\hline $\mathrm{Fe}_{3} \mathrm{O}_{4}$ & 55.1 & 1.4 & 13.6 & $25.2 \times 10^{-3}$ \\
\hline $\mathrm{Fe}_{3} \mathrm{O}_{4}-\mathrm{en}$ & 52.5 & 2.1 & 24.4 & $39.4 \times 10^{-3}$ \\
\hline $\mathrm{Fe}_{3} \mathrm{O}_{4}-\mathrm{ClT}$ & 44.7 & 1.1 & 13.1 & $23.7 \times 10^{-3}$ \\
\hline $\mathrm{Fe}_{3} \mathrm{O}_{4}-\mathrm{PPh}_{3}$ & 55.2 & 0.9 & 8.7 & $15.8 \times 10^{-3}$ \\
\hline
\end{tabular}


The analysis of Mössbauer spectra (MS) can provide very useful information on the oxidation of a magnetite surface. The same analysis cannot be performed with the XRD and TEM methods because of minor differences between the maghemite and magnetite unit cell parameters. To confirm the presence of maghemite on the surface of magnetite nanoparticles, the MS at room temperature were recorded for all samples and are presented in Figure 4. These spectra revealed asymmetrical six-line patterns with broad lines and were fitted using five to seven magnetic sextets and one single line. In turn, the obtained hyperfine parameters are summarized in Table 3. The full line widths at half maximum for all components were equal to $0.85 \mathrm{~mm} / \mathrm{s}$. The observed broad line width of the sextets confirmed the superparamagnetic size of the magnetite nanoparticles.

a

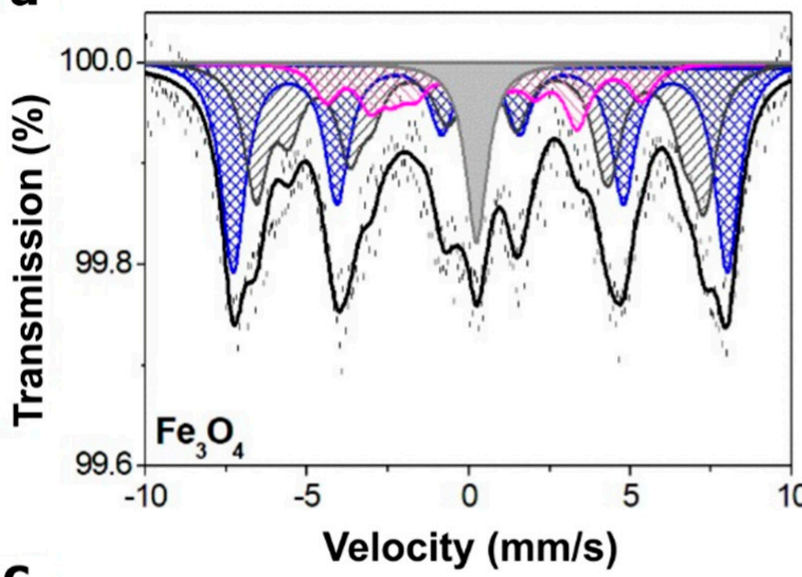

C

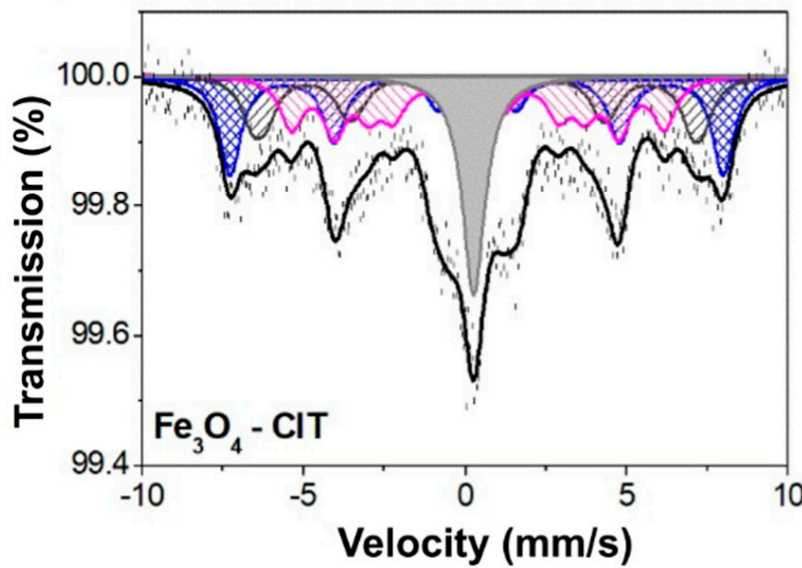

b
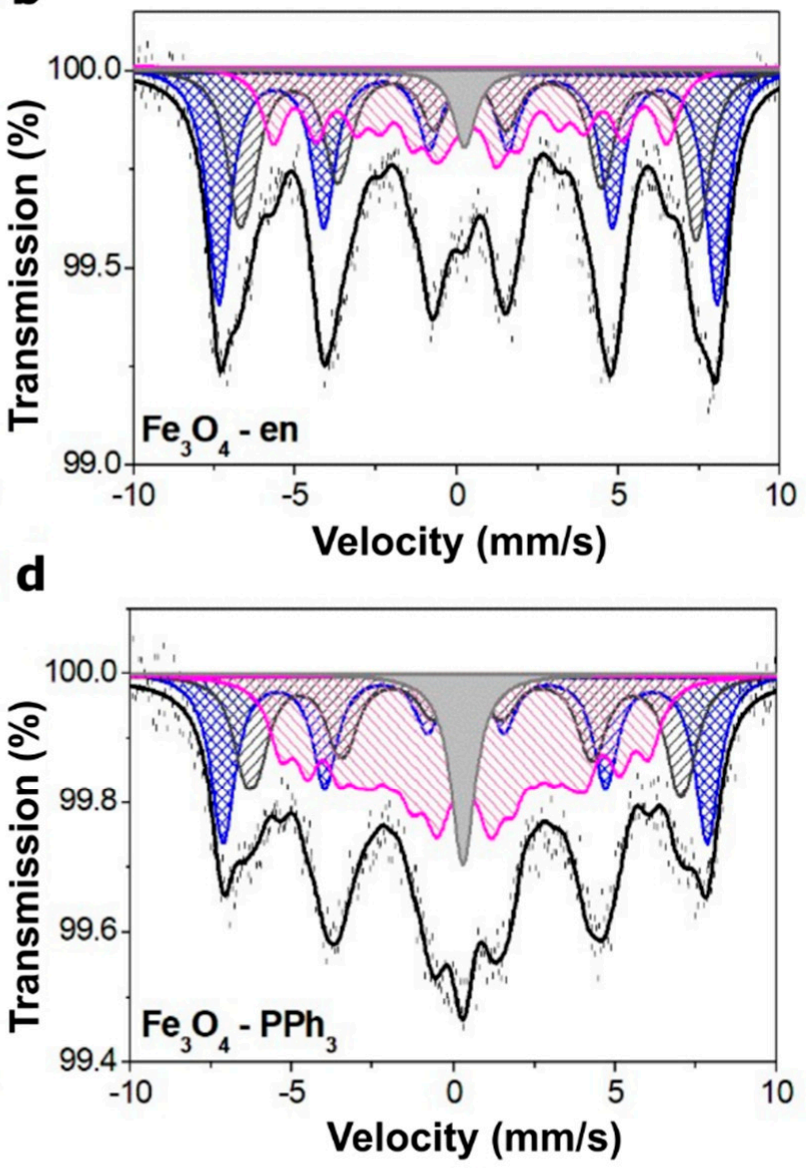

Figure 4. Mössbauer spectra of magnetite nanoparticles synthesized without (a) and with the presence of different organic modifiers: en (b), $\mathrm{ClT}(\mathbf{c})$, and $\mathrm{PPh}_{3}(\mathbf{d})$. The contribution of the $\gamma-\mathrm{Fe}_{2} \mathrm{O}_{3}$ is displayed in blue, and that of the $\mathrm{Fe}_{3} \mathrm{O}_{4}$ is displayed in dark grey; the sextets connected with the magnetic interaction between nanoparticles are displayed in magenta, and the contribution of superparamagnetic fine particles is displayed in light gray.

Note maghemite is cation-deficient spinel with $\mathrm{Fe}^{3+}$ on both the octahedral and tetrahedral sites. The contribution from $\mathrm{Fe}^{3+}$ on both sites of magnetically ordered maghemite led to the MS consisting of two sextets with similar hyperfine magnetic fields, essentially zero quadrupole splitting and isomer shifts characteristic for $\mathrm{Fe}^{3+}$ in tetrahedral and octahedral coordination. However, room-temperature MS of maghemite appeared as a single sextet (S1), which is evident since the contributions from $\mathrm{Fe}^{3+}$ ions at both sites of the maghemite spinel structure had close values. Sextets S2 and S3 represented iron ions located in the tetrahedral and octahedral sites in the $\mathrm{Fe}_{3} \mathrm{O}_{4}$ structure, respectively. Broader lines and smaller hyperfine fields can be a result of some non-stoichiometric of the crystals. 
Table 3. Hyperfine parameters of the synthesized samples (isomer shift $\left(I_{s}\right)$, quadrupole splitting $\left(Q_{s}\right)$, hyperfine magnetic field $(H)$, and relative area $(A))$.

\begin{tabular}{|c|c|c|c|c|c|c|c|c|c|}
\hline \multirow{2}{*}{ Sample } & \multirow{2}{*}{ Parameters } & \multicolumn{7}{|c|}{ Sextets } & \multirow{2}{*}{$\begin{array}{c}\text { Single Line } \\
\mathrm{L}\end{array}$} \\
\hline & & S1 & $\mathrm{S} 2$ & S3 & $\mathrm{S} 4$ & S5 & S6 & S7 & \\
\hline \multirow{4}{*}{$\mathrm{Fe}_{3} \mathrm{O}_{4}$} & $\mathrm{I}_{\mathrm{S}}(\mathrm{mm} / \mathrm{s})$ & 0.36 & 0.34 & 0.55 & 0.48 & 0.18 & \multirow{4}{*}{-} & \multirow{4}{*}{-} & 0.26 \\
\hline & $\mathrm{Q}_{\mathrm{s}}(\mathrm{mm} /)$ & 0.00 & 0.01 & 0.00 & -0.01 & -0.02 & & & - \\
\hline & $\mathrm{H}(\mathrm{T})$ & 47.6 & 43.2 & 38.2 & 30.3 & 19.9 & & & - \\
\hline & A (\%) & 41 & 25 & 12 & 7 & 7 & & & 8 \\
\hline \multirow{4}{*}{$\mathrm{Fe}_{3} \mathrm{O}_{4}$-en } & $\mathrm{I}_{\mathrm{S}}(\mathrm{mm} / \mathrm{s})$ & 0.32 & 0.26 & 0.56 & 0.36 & 0.34 & 0.18 & \multirow{4}{*}{-} & 0.17 \\
\hline & $\mathrm{Q}_{\mathrm{s}}(\mathrm{mm} /)$ & 0.00 & -0.01 & 0.02 & 0.00 & 0.01 & 0.03 & & - \\
\hline & $\mathrm{H}(\mathrm{T})$ & 47.9 & 43.9 & 43.0 & 37.9 & 29.5 & 10.4 & & - \\
\hline & $\mathrm{A}(\%)$ & 38 & 19 & 10 & 12 & 10 & 8 & & 3 \\
\hline \multirow{4}{*}{$\mathrm{Fe}_{3} \mathrm{O}_{4}-\mathrm{ClT}$} & $\mathrm{I}_{\mathrm{s}}(\mathrm{mm} / \mathrm{s})$ & 0.37 & 0.25 & 0.60 & 0.39 & 0.36 & 0.32 & \multirow{4}{*}{-} & 0.37 \\
\hline & $\mathrm{Q}_{\mathrm{s}}(\mathrm{mm} /)$ & 0.00 & -0.02 & 0.02 & 0.03 & 0.02 & -0.01 & & - \\
\hline & $\mathrm{H}(\mathrm{T})$ & 47.2 & 42.8 & 41.8 & 35.8 & 27.3 & 8.6 & & - \\
\hline & $\mathrm{A}(\%)$ & 23 & 11 & 9 & 13 & 15 & 12 & & 15 \\
\hline \multirow{4}{*}{$\mathrm{Fe}_{3} \mathrm{O}_{4}-\mathrm{PPh}_{3}$} & $\mathrm{I}_{\mathrm{S}}(\mathrm{mm} / \mathrm{s})$ & 0.37 & 0.26 & 0.60 & 0.35 & 0.31 & 0.29 & 0.29 & 0.28 \\
\hline & $\mathrm{Q}_{\mathrm{s}}(\mathrm{mm} /)$ & 0.00 & -0.01 & 0.00 & 0.01 & 0.02 & -0.02 & -0.02 & - \\
\hline & $\mathrm{H}(\mathrm{T})$ & 46.9 & 41.8 & 41.4 & 35.4 & 29.9 & 23.8 & 9.7 & - \\
\hline & A $(\%)$ & 27 & 12 & 10 & 10 & 11 & 10 & 12 & 8 \\
\hline
\end{tabular}

The MS of bulk magnetite is different than for nanoparticles, which is associated with a high contribution from the surface of nanoparticles, which is very important at the nanoscale and cannot be neglected. Furthermore, in the case of nanoparticles, much more sextets can be observed. Some are related to the maghemite formation on the magnetite surface, and others are associated to the external region and the transition layer between the external and internal regions. In the external region, $\mathrm{Fe}^{3+}$ ions are characterized by different magnetic properties due to the lack of adjacent ions and a new type of bond with organic molecules. Furthermore, $\mathrm{Fe}^{3+}$ ions are surrounded by two different types of ions in the transition layer from the core and the surface. Consequently, their properties are also different from the ions in the core of the nanoparticles. In all patterns, one can see these sextets marked in Table 3 as S4, S5, S6 and S7. The existence of these sextets has also been confirmed and described recently $[11,31]$.

All spectra also contained a single line (L). As can be seen, the contribution from the $\mathrm{L}$ component was the highest for nanoparticles synthesized using $\mathrm{ClT}$ and those from $\mathrm{Fe}_{3} \mathrm{O}_{4}$ and $\mathrm{Fe}_{3} \mathrm{O}_{4}-\mathrm{PPh}_{3} \mathrm{NPs}$ were the same. This component could arise from the cation vacancies and some superparamagnetic fine particles with no magnetic hyperfine splitting due to a lack of proper magnetic interactions. On the other hand, the analysis of the S1 sextets allowed us to state that the highest content of the oxidized layered had magnetite synthesized without any modifiers and $\mathrm{Fe}_{3} \mathrm{O}_{4}$-en NPs. The lowest contribution from $\gamma-\mathrm{Fe}_{2} \mathrm{O}_{3}$ was noted for $\mathrm{Fe}_{3} \mathrm{O}_{4}-\mathrm{ClT}$ and $\mathrm{Fe}_{3} \mathrm{O}_{4}-\mathrm{PPh}_{3} \mathrm{NPs}$. However, the high contribution from the single line suggests other non-magnetic particles in the sample synthesized in the presence of ClT.

\subsection{Dielectric Properties of Magnetite Nanoparticles with Different Sizes, Shapes, and Maghemite Contents}

For all the synthesized samples, the dielectric properties of $\mathrm{Fe}_{3} \mathrm{O}_{4} @ \gamma-\mathrm{Fe}_{2} \mathrm{O}_{3}$ nanoparticles with a core-shell structure were measured as a function of frequency and temperature. The obtained dielectric spectra, i.e., the real and imaginary parts of electric permittivity and the loss tangent, are presented in Figure 5. Complex electric permittivity $\varepsilon^{*}$ can be expressed as $\varepsilon^{\prime}+i \varepsilon^{\prime \prime}$, and the loss factor $\tan \delta$ can be described as the ratio of $\varepsilon^{\prime \prime} / \varepsilon^{\prime}$. $\varepsilon^{*}$ was 
measured by the dielectric spectroscopy indirectly by measuring complex capacitance $C^{*}$ and calculated by Equation (1) [32,33]:

$$
C^{*}=\varepsilon^{*} \varepsilon_{0} A / h,
$$

where $\varepsilon_{0}$ is the vacuum permittivity $\left(8.85 \times 10^{-12} \mathrm{As} /(\mathrm{V} \cdot \mathrm{m})\right), A$ is the surface area, and $h$ is the height of the measured sample.

In Figure 5, the electrical permittivity characteristics for various ferrites are shown. At low frequencies $(10 \mathrm{~Hz})$ and low temperatures, it is possible to determine the plateau region (in which $\varepsilon^{\prime}$ was nearly frequency-independent and can be marked as $\varepsilon_{\text {const }}^{\prime}$ ) for magnetite nanoparticles containing high $\gamma-\mathrm{Fe}_{2} \mathrm{O}_{3}$ content. The $\varepsilon^{\prime}$ const for $\mathrm{Fe}_{3} \mathrm{O}_{4} \mathrm{NPs}$ was equal to 61, that for $\mathrm{Fe}_{3} \mathrm{O}_{4}$-en NPs was 192, and that for $\mathrm{Fe}_{3} \mathrm{O}_{4}-\mathrm{ClT}$ NPs was 185, all of which

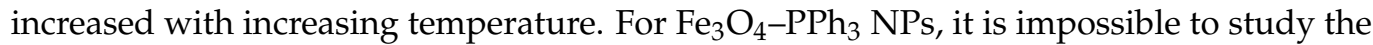
low-frequency $\varepsilon^{\prime}$, especially in high-temperature regions. It is known, from the structural analysis, that these nanoparticles were cuboidal and had relatively low maghemite content.

The presence of the plateau region and the $\varepsilon^{\prime}$ dispersion in the high-frequency range is associated with the Maxwell-Wagner polarization, which is characteristic of inhomogeneous samples, such as highly conductive particles covered with a resistive surface. The analysis of only the low-frequency region can allow observing that the polarization phenomenon in these nanoparticles is related to the interfacial polarization [34]. As the temperature rises, much more charge carriers accumulate on the surface of the particles, and this polarization is clearly visible. Interestingly, at high temperatures, the role of the magnetite shape, maghemite content, presence of organic molecules, cations vacancies, and surface disordering is very important. For example, at $353 \mathrm{~K}$ and $10 \mathrm{~Hz}, \varepsilon^{\prime}$ for spherically shaped $\mathrm{Fe}_{3} \mathrm{O}_{4}$ NPs was equal to 329, whereas that for cuboidally shaped $\mathrm{Fe}_{3} \mathrm{O}_{4}$-en NPs was 53,409. Accordingly, the accumulation of electrons increased with the introduction of the maghemite layer onto the magnetite surface and by crystallizing nanoparticles into cuboidal particles with a highly disordered surface.

Interestingly, for $\mathrm{Fe}_{3} \mathrm{O}_{4}-\mathrm{PPh}_{3} \mathrm{NPs}$ with a low $\gamma-\mathrm{Fe}_{2} \mathrm{O}_{3}$ content, the possibility of the electrons accumulation on the surface of the particles was negligible. In the low-frequency region, only the fluctuation of $\varepsilon^{\prime}$ can be observed, which is related to the high mobility of electrons and high conductivity in this sample, which will be discussed later. The question is: why does the change of shape and surface chemical composition increase the $\varepsilon^{\prime}$ value so drastically? When analyzing this type of nanoparticles, it can be seen that the low-frequency electron transport did not occur from the surface of one nanoparticle to the surface of the second one, but through the disordered $\gamma-\mathrm{Fe}_{2} \mathrm{O}_{3}$ layer. Accordingly, the accumulation of charge carriers occurred on highly defected, more resistive $\gamma-\mathrm{Fe}_{2} \mathrm{O}_{3}$ surfaces containing many different defects such as iron vacancies and dislocations $[4,14]$.

The real part of the permittivity is related to the degree of polarization, while the imaginary one provides information about dielectric losses. The $\varepsilon^{\prime \prime}(f)$ behavior for a wide temperature range from 173 to $363 \mathrm{~K}$ is shown in Figure $5 \mathrm{~b}$. As can be seen, $\varepsilon^{\prime \prime}$ values are similar for all samples; however, in the low-temperature range, much higher values were observed for the $\mathrm{Fe}_{3} \mathrm{O}_{4}-\mathrm{PPh}_{3}$ sample. The analysis of dielectric losses can be carried out in the context of the loss tangent, which can represent the energy dissipation in the material under the influence of an applied AC electromagnetic field and for various applications such as supercapacitors should be minimized [35]. In general, increasing the defect density results in higher $\tan \delta$ values, which have been confirmed in the literature [36]. These defects can be related to the presence of impurities and any imperfections in the crystalline structure.

Interestingly, $\tan \delta$ did not depend on the maghemite concentration but is closely related to the average crystallite size. Higher dielectric losses were observed for nanoparticles with $D_{H-W}$ equal to $8.04 \mathrm{~nm}\left(\mathrm{Fe}_{3} \mathrm{O}_{4}-\mathrm{PPh}_{3}\right)$ and the lowest was identified for $\mathrm{Fe}_{3} \mathrm{O}_{4}$-en NPs with an average crystallite size equal to $11.8 \mathrm{~nm}$. Thus, the storage properties were strongly related to the disordering and oxidation of the magnetite surface and their dissipation properties with their size. 

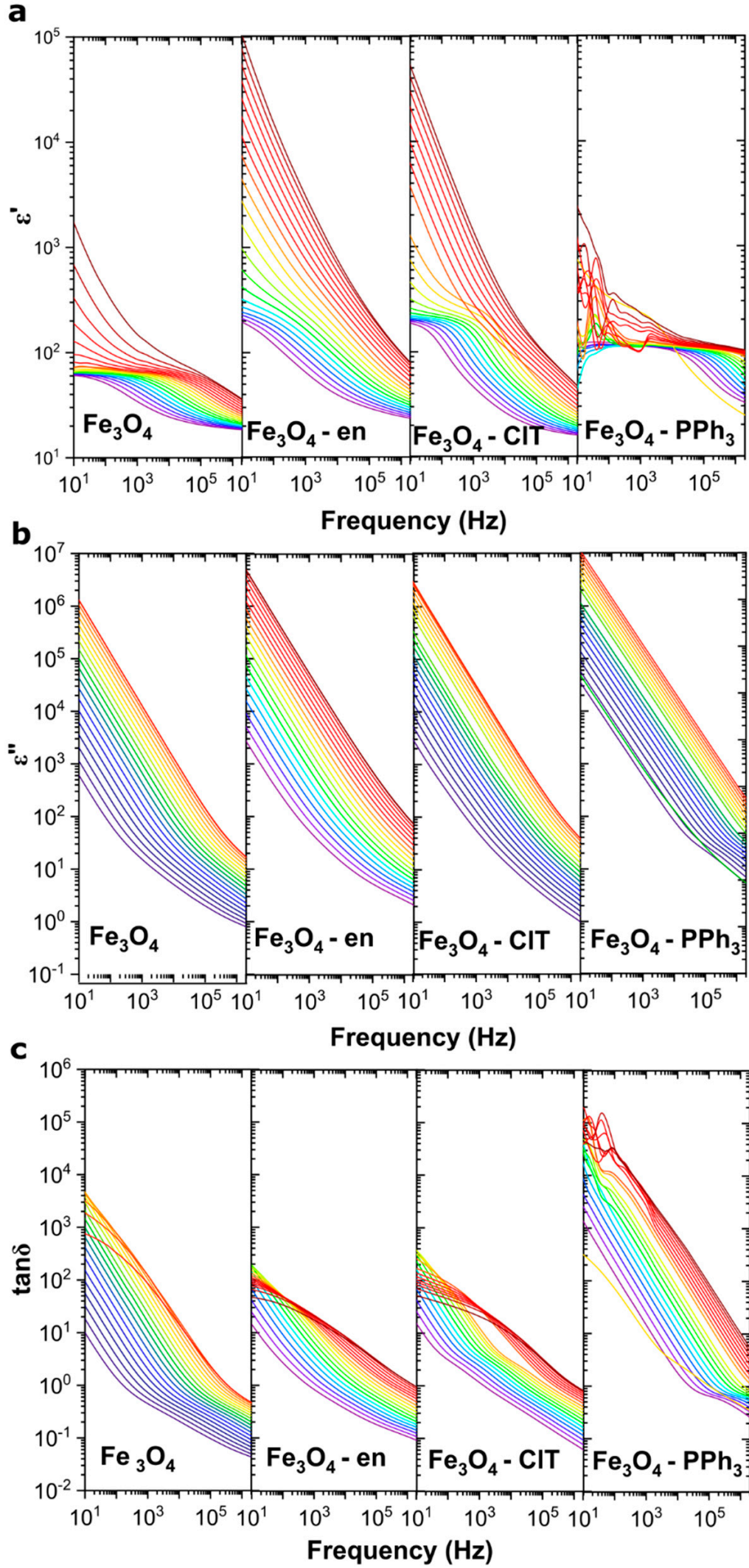

Figure 5. Dielectric properties of magnetite nanoparticles with different shapes and oxidized surfaces: real (a) and imaginary (b) parts of permittivity, (c) loss tangents in different temperatures from $173 \mathrm{~K}$ (violet line) to $363 \mathrm{~K}$ (red line) with $\Delta \mathrm{T}=10 \mathrm{~K}$. 


\subsection{Electrical Conductivity of Magnetite Nanoparticles}

The electrical conductivity of magnetite nanoparticles with a modified surface and shape was determined based on measurements of complex electrical conductivity and complex dielectric modulus. The electrical conductivity $\sigma^{*}$ is related to the electrical permittivity according to Equation (2), and the complex dielectric modulus $\left(M^{*}\right)$ is given by Equation (3) [33,37]:

$$
\begin{gathered}
\sigma^{*}=\sigma^{\prime}-i \sigma^{\prime \prime}=i 2 \pi f \varepsilon_{0} \varepsilon^{*}, \\
M^{*}=M^{\prime}-i M^{\prime \prime}=1 / \varepsilon^{*} .
\end{gathered}
$$

The analysis of complex electrical conductivity can provide information about the lag in the movements of charge carriers associated with rapid changes of the electric field and information about their movement, type of electrical conductivity mechanism, and even DC conductivity. The complex dielectric modulus can be used to determine the number of electric processes in materials and the relaxation time of the transition between long- and short-range charge carriers motions (especially in heterogeneous systems) [38]. The imaginary part of the dielectric modulus $M^{\prime \prime}$, together with the real part of electrical conductivity $\sigma^{\prime}$, is presented in Figure 6 . As can be seen, both $M^{\prime \prime}$ and $\sigma^{\prime}$ were different for all synthesized nanoparticles. The most visible changes can be observed for the electrical conductivity of $\mathrm{Fe}_{3} \mathrm{O}_{4} \mathrm{NPs}$ and $\mathrm{Fe}_{3} \mathrm{O}_{4}-\mathrm{PPh}_{3} \mathrm{NPs}$. The $\sigma^{\prime}$ value at the low-frequency region was a few orders higher for nanoparticles synthesized in the presence of $\mathrm{PPh}_{3}$. These nanoparticles were characterized by the low concentration of the maghemite phase, cuboidal shape, and the surface free from organic modifiers. The low-frequency electrical conductivities of $\mathrm{Fe}_{3} \mathrm{O}_{4}$-en and $\mathrm{Fe}_{3} \mathrm{O}_{4}-\mathrm{ClT}$ NPs were similar and higher than that of pure $\mathrm{Fe}_{3} \mathrm{O}_{4}$ NPs. It is well-known that low-frequency conductivity is closely related to the slow movement of charge carriers through the particle surface and high frequency to the movement of charge carriers in particles. The transition between these processes can be determined based on the analysis of the $M^{\prime \prime}$ peak [16]. The presence of an oxidized and disordered surface, organic modifiers, and different shapes drastically change the electrical properties, especially in the low-frequency region, where the surface plays a crucial role in the movement of charge carriers. Accordingly, the oxidized surface of $\mathrm{Fe}_{3} \mathrm{O}_{4}{ }^{-}$ en NPs and the additional presence of non-magnetic ultrafine particles in $\mathrm{Fe}_{3} \mathrm{O}_{4}-\mathrm{ClT}$ NPs caused a decrease in the electrical conductivity in the low-frequency region compared to in spherically shaped $\mathrm{Fe}_{3} \mathrm{O}_{4}-\mathrm{PPh}_{3} \mathrm{NPs}$. The conductivity of the pure $\mathrm{Fe}_{3} \mathrm{O}_{4} \mathrm{NPs}$ was the lowest and related to their spherical shape and the highest maghemite content. In addition, the shapes and maximum positions of the $M^{\prime \prime}$ peak were different for all nanoparticles and were related to the oxidation and functionalization of their surface. The dual nature of the $M^{\prime \prime}$ peak was visible for $\mathrm{Fe}_{3} \mathrm{O}_{4}-\mathrm{PPh}_{3} \mathrm{NPs}$, for which the content of the maghemite phase was relatively low. According to previous studies [11], the high-frequency peak is related to the movements of electrons in the magnetite, while the visible shoulder to their movements in the maghemite. For cuboidal $\mathrm{Fe}_{3} \mathrm{O}_{4}-\mathrm{ClT}$ NPs containing especially nonmagnetic particles, the dual nature of the peak cannot be observed, but for other samples, the presence of broad peaks was related to the overlapping of these two electrical processes.

The modified universal power law (Equation (4)) was used to determine the mechanism of electrical conductivity that occurs in the magnetite nanoparticles with an oxidized and disordered surface. This model, unlike the universal power law, can be used to fit the real and imaginary parts of a complex conductivity simultaneously [17]:

$$
\sigma^{*}=\sigma_{D C}+A_{1} \omega^{n}-i A_{2} \omega^{n},
$$

where $\sigma_{D C}$ is the DC conductivity, $A_{1}$ and $A_{2}$ preexponential factors, and $n$ is the exponent, which can be used to determine the electrical conductivity mechanism. 


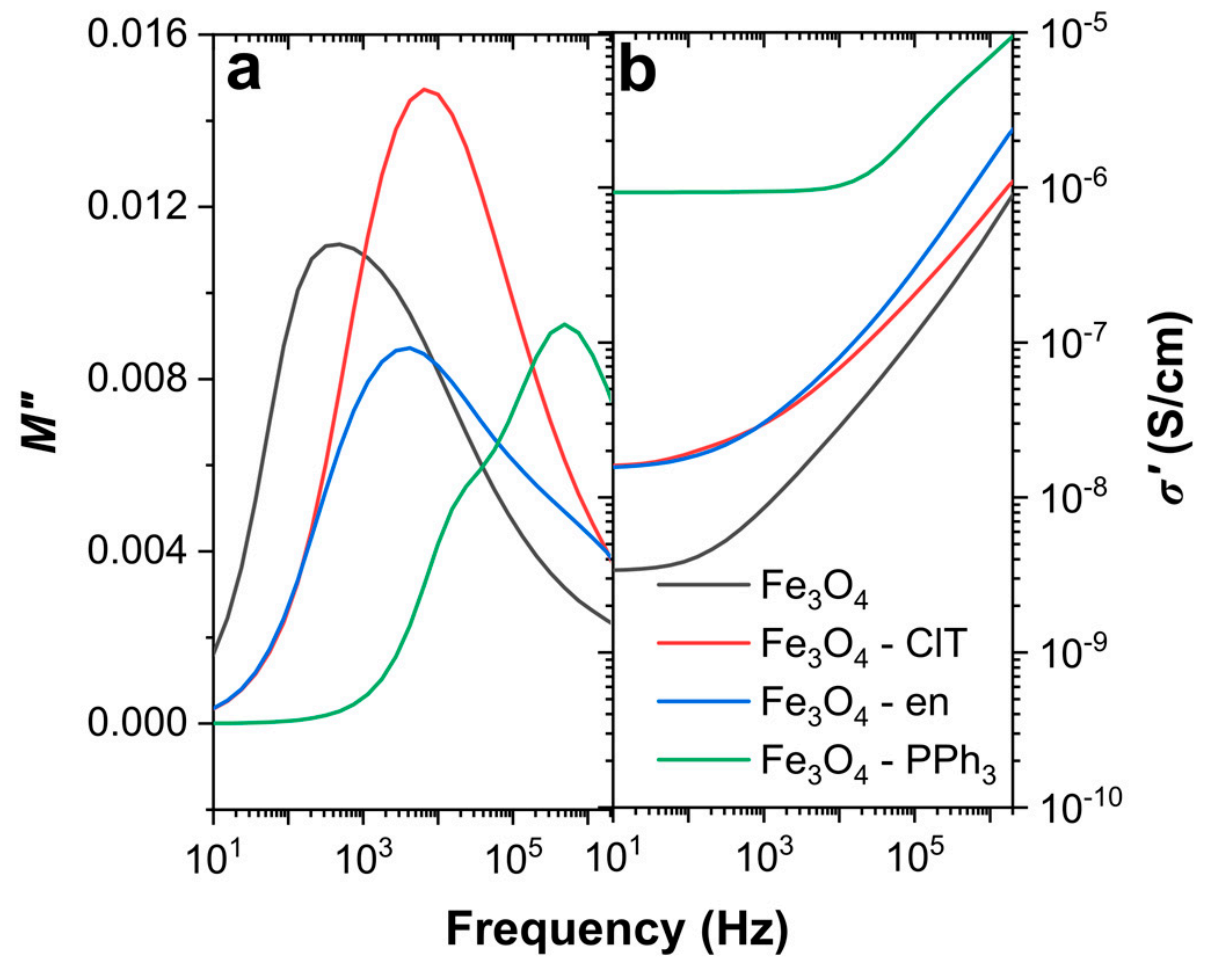

Figure 6. Comparison of electric properties of magnetite nanoparticles at a constant temperature equal to $173 \mathrm{~K}$ : (a) imaginary part of the dielectric modulus; and (b) real part of the electrical conductivity.

The applicability of this model has recently been validated for magnetite nanoparticles and allowed for a better fit of the theoretical model to the experimental data. The simultaneous fitting of the real and imaginary parts of the electrical conductivity can result in different $n(T)$ behaviors that can be used to describe the high-frequency behavior. Therefore, this approach should also allow for an accurate and comprehensive analysis of the behavior of the electrons in oxidized magnetite nanoparticles with various shapes. In general, when exponent $n$ decreases with increasing temperature, the correlated barrier hopping $(\mathrm{CBH})$ can be used to describe their behavior; when exponent $n$ increases with increasing temperature, non-overlapping small polaron tunneling (NSPT) occurs [16]. In some cases, the non-linear behavior of this exponent can be observed. For example, when $n$ drops to a minimum value and then increases with increasing temperature, overlapping large polaron tunneling (OLPT) occurs [17]. The quantum mechanical tunneling appears when the $n$ value equals 0.8 , and only slight changes in its value generated by the temperatures can be observed [39]. Additionally, DC electrical conductivity related to the motion of the electrons through the surface of particles in the low-frequency region can be determined from the modified universal power law. In general, this process is highly temperature-dependent, and the activation energy can be estimated based on the Arrhenius law [40].

Figure $7 \mathrm{a}-\mathrm{d}$ shows the real and imaginary parts of the electrical conductivity at $273 \mathrm{~K}$, along with the theoretical curves obtained from the fitting by Equation (4). As can be seen, the modified universal power law can be successfully used to describe the complex electrical conductivity over the entire frequency range for samples with relatively low electrical conductivity. Only for $\mathrm{Fe}_{3} \mathrm{O}_{4}-\mathrm{PPh}_{3} \mathrm{NPs}$, the applicability of this model is limited. However, despite the fact that the modified universal power law cannot describe the real part of electrical conductivity, the imaginary one was very well described by the proposed model. 

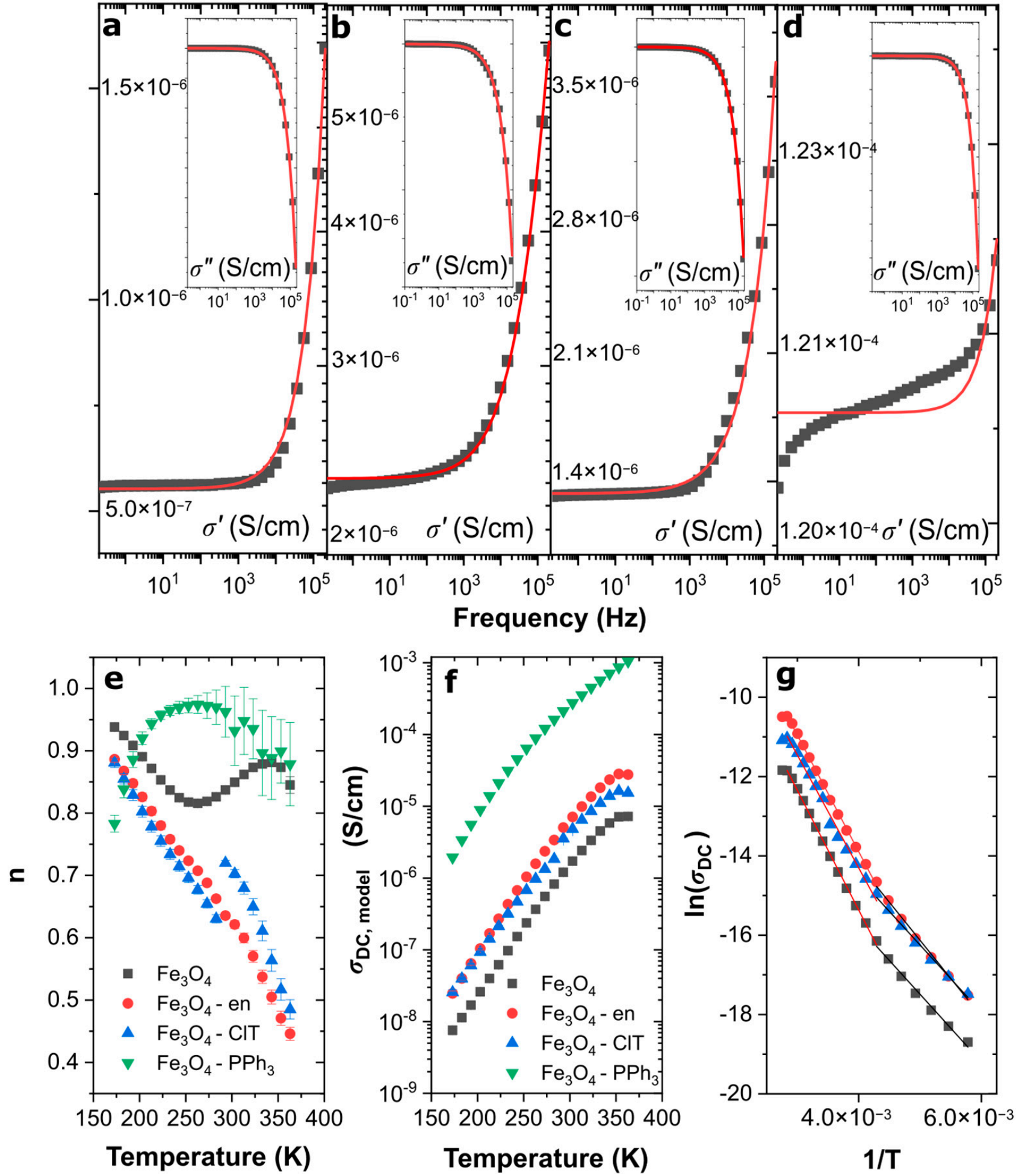

Figure 7. Electrical conductivity for magnetite nanoparticles with different shapes and oxidized surfaces: fitting of the

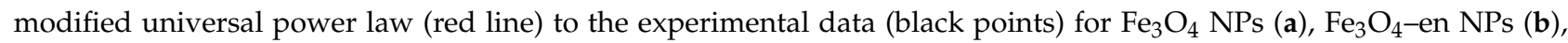
$\mathrm{Fe}_{3} \mathrm{O}_{4}-\mathrm{ClT}$ NPs (c), and $\mathrm{Fe}_{3} \mathrm{O}_{4}-\mathrm{PPh}_{3} \mathrm{NPs}(\mathbf{d})$. The insets shows the imaginary part of the electrical conductivity; (e) the $n(T)$ behavior in temperature function with marked measurement errors; (f) changes in $\sigma_{D C}$ value generated by the temperature changes; (g) Arrhenius plots with the fitted curves confirming the existence of two different electrical processes.

The model and experimental data differences are strongly related to the ultrafast electron transport between ultrafine magnetite nanoparticles with low maghemite content and cuboidal shape. When for other samples, there was an accumulation and slow motion 
of electrons on the disordered and oxidized surface (which was discussed in the context of electric permittivity) for $\mathrm{Fe}_{3} \mathrm{O}_{4}-\mathrm{PPh}_{3} \mathrm{NPs}$, electrons can be easily transferred through the particles surface to the electrodes, which is manifested in a significant drop in $\sigma^{\prime}$ at high temperatures and in a low-frequency region. It is also visible in the difference between the values of the low-frequency conductivity for the analyzed samples. For example, $\sigma^{\prime}$ equaled $1.33 \times 10^{-6} \mathrm{~S} / \mathrm{cm}\left(\right.$ at $10 \mathrm{~Hz}$ ) for $\mathrm{Fe}_{3} \mathrm{O}_{4}-\mathrm{ClT}$ NPs, whereas $\sigma^{\prime}$ for $\mathrm{Fe}_{3} \mathrm{O}_{4}-\mathrm{PPh}_{3}$ NPs was 100 times higher $\left(1.02 \times 10^{-4} \mathrm{~S} / \mathrm{cm}\right.$ at $\left.10 \mathrm{~Hz}\right)$. Therefore, the calculation of the $n(T)$ behavior for $\mathrm{Fe}_{3} \mathrm{O}_{4}-\mathrm{PPh}_{3}$ NPs was burdened with a significant error, especially in the case of high temperatures, which can be observed in Figure 7e. On the other hand, in a low-temperature region, where the mobility of electrons in magnetite was low, the $n(T)$ behaviors for these particles were characteristic of the NSPT model, which was also theoretically confirmed using DFT $+\mathrm{U}$ and hybrid functional calculations [41].

At high temperatures, the ultrafine cuboidal nanoparticles with $n \approx 1$ should behave similarly to the ideal Debye dielectric dipolar-type crystal. However, the other situation arose in the $n(T)$ analysis for oxidized samples. While the surface of the oxidized nearly spherical nanoparticles $\left(\mathrm{Fe}_{3} \mathrm{O}_{4} \mathrm{NPs}\right.$ ) was free of organic molecules, OLPT occurred. However, correlated barrier hopping occurred when nanoparticles crystallized into cuboidal forms, and organic molecules functionalized their oxidized surfaces (such as ClT and en).

Figure $7 \mathrm{f}$ shows the relationship between the DC electrical conductivity obtained from the modified universal power law and temperature. While the $\sigma_{D C}$ values for spherically shaped and highly oxidized samples can be satisfactorily analyzed, the $\sigma_{D C}$ for $\mathrm{Fe}_{3} \mathrm{O}_{4}-\mathrm{PPh}_{3}$ NPs was presented only illustratively, because in this type of material, the experimental data did not stay in good agreement with the theoretical model (see Figure 7d). However, with increasing temperature, an increasing tendency of electrical conductivity can be observed for all materials. It is related to the mobility of electrons, which is strongly dependent on temperature. Moreover, it is possible to determine activation energies $E_{a}$ of electrons moving through the surface of particles. Accordingly, Figure $7 \mathrm{~g}$ shows the Arrhenius plots for the oxidized samples. The $\mathrm{Fe}_{3} \mathrm{O}_{4}-\mathrm{PPh}_{3} \mathrm{NPs}$ were not analyzed, because the obtained values had a high error. Interestingly, all analyzed samples were characterized by two different activation energies, in low- (173-233 K) and high- temperature (243-363 K) ranges. The calculated values of $E_{a}$ are listed in Table 4 . As one can see, the values of both processes were similar for all nanoparticles $\left(\Delta E_{a}\right.$ was not higher than $\left.\pm 0.02 \mathrm{eV}\right)$, because the movement of the charge carriers through the surface occurred in $\gamma-\mathrm{Fe}_{2} \mathrm{O}_{3}$ and it did not depend on the shape, size, and functionalization. It is well-known that the transport of electrons in magnetite is much easier than in maghemite and is related to the electrons hopping between $\mathrm{Fe}^{3+}$ and $\mathrm{Fe}^{2+}$ ions [41]. When the magnetite surface is blocked by other non-magnetic nanoparticles, high disordering, or $\gamma-\mathrm{Fe}_{2} \mathrm{O}_{3}$, in which only $\mathrm{Fe}^{3+}$ and iron vacancies exist, the electron movement becomes slower $[4,14,42]$. In high-temperature regions, movement of electrons increases; however, negatively charged cation vacancies and thermal vibrations of the lattice structure appear. Accordingly, the energy required for this process is much higher than for the low-energy region, in which conductivity is much lower, and electrons can slowly move through the particle surface.

Table 4. Activation energies $\left(E_{a}\right)$ of electrical conductivity in low- (173-233 K) and high-temperature (243-363 K) ranges determined from Arrhenius plots.

\begin{tabular}{ccc}
\hline Sample & $E_{\text {a,low T }}(\mathbf{e V})$ & $E_{\text {a,highT }}(\mathrm{eV})$ \\
\hline $\mathrm{Fe}_{3} \mathrm{O}_{4}$ & 0.15 & 0.26 \\
\hline $\mathrm{Fe}_{3} \mathrm{O}_{4}-\mathrm{en}$ & 0.17 & 0.25 \\
\hline $\mathrm{Fe}_{3} \mathrm{O}_{4}-\mathrm{ClT}$ & 0.15 & 0.24 \\
\hline
\end{tabular}

Based on the comprehensive analysis of the structure and properties of magnetite nanoparticles synthesized in a hydrophobic-hydrophilic environment performed above, it can be concluded that there is a possibility to synthesize $\mathrm{Fe}_{3} \mathrm{O}_{4}$ NPs with determined prop- 
erties. For example, when good magnetic properties could characterize the nanoparticles, we can adjust the synthesis conditions to maintain these properties and obtain nanoparticles that are excellent electrically conductive $\left(\mathrm{Fe}_{3} \mathrm{O}_{4}-\mathrm{PPh}_{3} \mathrm{NPs}\right)$ or have a high ability to store charges on their surface $\left(\mathrm{Fe}_{3} \mathrm{O}_{4} \mathrm{NPs}\right)$. Both samples have similar and high $M_{s}$ and low $H_{c}$ values; however, the electrical conductivity of spherically shaped $\mathrm{Fe}_{3} \mathrm{O}_{4} \mathrm{NPs}$ can be even 1000 times lower than $\mathrm{Fe}_{3} \mathrm{O}_{4}-\mathrm{PPh}_{3} \mathrm{NPs}$ at low temperature and in a low-frequency range. However, when the magnetite nanoparticles are used as a capacitor, $\mathrm{Fe}_{3} \mathrm{O}_{4}$-en and $\mathrm{Fe}_{3} \mathrm{O}_{4}$-CIT NPs should be used according to their high $\varepsilon^{\prime}$ and low $\tan \delta$ values in wide temperature and frequency ranges [35].

\section{Conclusions}

The surface modification of magnetite plays a key role in synthesizing nanoparticles with specific properties, such as catalytic activity, biocompatibility, and magnetic and dielectric properties. Herein, the possibility of synthesizing ultrafine $(9.6 \pm 2.0)$ cuboidal nanoparticles with a relatively low content of an oxidized layer using $\mathrm{PPh}_{3}$ as an organic modifier have been confirmed. For these nanoparticles, the highest electrical conductivity (about 1000 times higher than for spherically shaped nanoparticles) and the best superparamagnetic properties ( $M_{s}$ equal to $55.2 \mathrm{emu} / \mathrm{g}$ and $H_{c}$ equal to $8.7 \mathrm{Oe}$ ) have been observed. Furthermore, it was confirmed that the transformation of magnetite into maghemite and the copresence of ultrafine non-magnetic nanoparticles caused a decrease in saturation magnetization ( $44.75 \mathrm{emu} / \mathrm{g}$ for the $\mathrm{Fe}_{3} \mathrm{O}_{4}-\mathrm{ClT} \mathrm{NPs}$ ). Interestingly, the electric energy storage properties are strictly related to surface disordering and composition. Therefore, $\varepsilon^{\prime}$ was the highest for $\mathrm{Fe}_{3} \mathrm{O}_{4}$-en NPs and $\mathrm{Fe}_{3} \mathrm{O}_{4}-\mathrm{ClT} \mathrm{NPs}$, for which the oxidized layer, surface disordering and presence of non-magnetic particles or cation vacancies were observed.

On the other hand, dielectric losses are not attributed to an oxidized layer and can be connected with the size of particles. The analysis of the electrical conductivity and the imaginary part of the electric modulus confirmed the high impact of the oxidized surface on the electron behavior. In the $M^{\prime \prime}$ spectra, a double peak related to the transition between two electric processes has been observed. Moreover, applying the modified universal power law allowed determining the DC conductivity, the activation energy of electron movements through the surface, and the electrical conductivity mechanism. Interestingly, only in the case of $\mathrm{Fe}_{3} \mathrm{O}_{4}-\mathrm{PPh}_{3} \mathrm{NPs}$, the application of this model was not possible, especially in regions of high temperature. However, the electron behavior and electrical conductivity for $\mathrm{Fe}_{3} \mathrm{O}_{4}-\mathrm{PPh}_{3} \mathrm{NPs}$ can be described using non-overlapping small polaron tunneling in a low-temperature range.

In contrast, at higher temperatures, the behavior of this sample is similar to the ideal Debye dielectric dipolar-type crystal. The electrical conductivity mechanism is also different for nanoparticles with variable $\gamma-\mathrm{Fe}_{2} \mathrm{O}_{3}$ contents and with a different shape. For $\mathrm{Fe}_{3} \mathrm{O}_{4}$-en NPs and $\mathrm{Fe}_{3} \mathrm{O}_{4}$-CIT NPs, the high-frequency electrical conductivity mechanism is related to the $\mathrm{CBH}$ model, whereas for $\mathrm{Fe}_{3} \mathrm{O}_{4}$ NPs it is associated with OLPT model. Accordingly, the presented results can be used to synthesize magnetite nanoparticles with defined magnetic and dielectric properties by modifying the synthesis route. As confirmed, it is simple to prepare $\mathrm{Fe}_{3} \mathrm{O}_{4}$ nanoparticles with similar magnetic properties, whereas their electrical conductivity can differ by a few orders. Moreover, further research should develop restrictions needed at the synthesis step to obtain materials for chosen applications.

Author Contributions: Conceptualization, A.R., D.Ł. and R.B.; formal analysis, M.K.-G.; investigation, A.R., M.K.-G., D.Ł., A.K.-B., P.G., P.W. and M.P.; methodology, M.K.-G., D.Ł. and P.G.; supervision, K.C.-A. and R.B.; validation, M.P.; writing—the original draft, A.R.; writing-review \& editing, A.R., K.C.-A., A.K.-B., P.W., M.P. and R.B. All authors have read and agreed to the published version of the manuscript.

Funding: This work was funded by the Polish Ministry of Science and Higher Education Diamond Grant VII (grant number: 0220/DIA/2018/470) and was supported by the Silesian University of Technology, Poland (grant number: 10/010/BKM21/1053). 
Institutional Review Board Statement: Not applicable.

Informed Consent Statement: Not applicable.

Data Availability Statement: The data presented in this study are available on request from the corresponding authors.

Conflicts of Interest: The authors declare no conflict of interest. The funders had no role in the design of the study; in the collection, analyses, or interpretation of data; in the writing of the manuscript, or in the decision to publish the results.

\section{References}

1. Kumar, R.; Mondal, K.; Panda, P.K.; Kaushik, A.; Abolhassani, R.; Ahuja, R.; Rubahn, H.G.; Mishra, Y.K. Core-shell nanostructures: Perspectives towards drug delivery applications. J. Mater. Chem. B 2020, 8, 8992-9027. [CrossRef]

2. Tan, L.; Wang, F.; Zhang, P.; Suzuki, Y.; Wu, Y.; Chen, J.; Yang, G.; Tsubaki, N. Design of a core-shell catalyst: An effective strategy for suppressing side reactions in syngas for direct selective conversion to light olefins. Chem. Sci. 2020, 11, 4097-4105. [CrossRef]

3. Kumar, N.; Sinha Ray, S. Synthesis and functionalization of nanomaterials. In Processing of Polymer-Based Nanocomposites; Springer Series in Materials Science; Sinha Ray, S., Ed.; Springer: Berlin/Heidelberg, Germany, 2018; Volume 277.

4. Natarajan, S.; Harini, K.; Gajula, G.P.; Sarmento, B.; Neves-Petersen, M.T.; Thiagarajan, V. Multifunctional magnetic iron oxide nanoparticles: Diverse synthetic approaches, surface modifications, cytotoxicity towards biomedical and industrial applications. BMC Mater. 2019, 1, 2. [CrossRef]

5. Majhi, S.M.; Naik, G.K.; Lee, H.J.; Song, H.G.; Lee, C.R.; Lee, I.H.; Yu, Y.T. Au@NiO core-shell nanoparticles as a p-type gas sensor: Novel synthesis, characterization, and their gas sensing properties with sensing mechanism. Sens. Actuators B Chem. 2018, 268, 223-231. [CrossRef]

6. Qu, F.; Liu, J.; Wang, Y.; Wen, S.; Chen, Y.; Li, X.; Ruan, S. Hierarchical $\mathrm{Fe}_{3} \mathrm{O}_{4} @ \mathrm{Co}_{3} \mathrm{O}_{4}$ core-shell microspheres: Preparation and acetone sensing properties. Sens. Actuators B Chem. 2014, 199, 346-353. [CrossRef]

7. Sappino, C.; Primitivo, L.; De Angelis, M.; Domenici, M.O.; Mastrodonato, A.; Romdan, I.B.; Tatangelo, C.; Suber, L.; Pilloni, L.; Ricelli, A.; et al. Functionalized Magnetic Nanoparticles as Catalysts for Enantioselective Henry Reaction. ACS Omega 2019, 4, 21809-21817. [CrossRef]

8. Ingle, A.P.; Philippini, R.R.; de Souza Melo, Y.C.; da Silva, S.S. Acid-functionalized magnetic nanocatalysts mediated pretreatment of sugarcane straw: An eco-friendly and cost-effective approach. Cellulose 2020, 27, 7067-7078. [CrossRef]

9. Xiong, F.; Hu, K.; Yu, H.; Zhou, L.; Song, L.; Zhang, Y.; Shan, X.; Liu, J.; Gu, N. A Functional Iron Oxide Nanoparticles Modified with PLA-PEG-DG as Tumor-Targeted MRI Contrast Agent. Pharm. Res. 2017, 34, 1683-1692. [CrossRef] [PubMed]

10. Salem, M.; Xia, Y.; Allan, A.; Rohani, S.; Gillies, E.R. Curcumin-loaded, folic acid-functionalized magnetite particles for targeted drug delivery. RSC Adv. 2015, 5, 37521-37532. [CrossRef]

11. Radoń, A.; Łoński, S.; Kądziołka-Gaweł, M.; Gębara, P.; Lis, M.; Łukowiec, D.; Babilas, R. Influence of magnetite nanoparticles surface dissolution, stabilization and functionalization by malonic acid on the catalytic activity, magnetic and electrical properties. Colloids Surf. A Physicochem. Eng. Asp. 2020, 607, 125446. [CrossRef]

12. $\mathrm{Wu}, \mathrm{W} . ; \mathrm{He}, \mathrm{Q} . ;$ Jiang, C. Magnetic iron oxide nanoparticles: Synthesis and surface functionalization strategies. Nanoscale Res. Lett. 2008, 3, 397-415. [CrossRef]

13. Schwaminger, S.P.; Bauer, D.; Fraga-García, P.; Wagner, F.E.; Berensmeier, S. Oxidation of magnetite nanoparticles: Impact on surface and crystal properties. CrystEngComm 2017, 19, 246-255. [CrossRef]

14. Winsett, J.; Moilanen, A.; Paudel, K.; Kamali, S.; Ding, K.; Cribb, W.; Seifu, D.; Neupane, S. Quantitative determination of magnetite and maghemite in iron oxide nanoparticles using Mössbauer spectroscopy. SN Appl. Sci. 2019, 1, 1636. [CrossRef]

15. Morales, I.; Costo, R.; Mille, N.; da Silva, G.B.; Carrey, J.; Hernando, A.; de la Presa, P. High frequency hysteresis losses on $\gamma$-Fe ${ }_{2} \mathrm{O}_{3}$ and $\mathrm{Fe}_{3} \mathrm{O}_{4}$ : Susceptibility as a magnetic stamp for chain formation. Nanomaterials 2018, 8, 970. [CrossRef]

16. Radoń, A.; Łukowiec, D.; Kremzer, M.; Mikuła, J.; Włodarczyk, P. Electrical conduction mechanism and dielectric properties of spherical shaped $\mathrm{Fe}_{3} \mathrm{O}_{4}$ nanoparticles synthesized by co-precipitation method. Materials (Basel) 2018, 11, 735. [CrossRef] [PubMed]

17. Radoń, A.; Łukowiec, D.; Włodarczyk, P. Ultraslow electron-phonon scattering and polaron formation in magnetite. J. Mater. 2021, in press.

18. Truncik, C.J.S.; Huttema, W.A.; Turner, P.J.; Özcan, S.; Murphy, N.C.; Carrière, P.R.; Thewalt, E.; Morse, K.J.; Koenig, A.J.; Sarrao, J.L.; et al. Nodal quasiparticle dynamics in the heavy fermion superconductor CeCoIn 5 revealed by precision microwave spectroscopy. Nat. Commun. 2013, 4, 2477. [CrossRef] [PubMed]

19. Kotnala, R.K.; Ahmad, S.; Ahmed, A.S.; Shah, J.; Azam, A. Investigation of structural, dielectric, and magnetic properties of hard and soft mixed ferrite composites. Proc. J. Appl. Phys. 2012, 112, 054323. [CrossRef]

20. Jotania, R.B.; Nandotaria, R.A.; Chauhan, C.C.; Hashim, M.; Singh Meena, S.; Shirsath, S.E. Structural phases and Maxwell-Wagner relaxation in magnetically soft- $\mathrm{ZnFe}_{2} \mathrm{O}_{4}$ and hard- $\mathrm{Sr}_{2} \mathrm{Cu}_{2} \mathrm{Fe}_{12} \mathrm{O}_{22}$ nanocomposites. Ceram. Int. 2016, 42, 2289-2298. [CrossRef]

21. Siregar, J.; Septiani, N.L.W.; Abrori, S.A.; Sebayang, K.; Irzaman; Fahmi, M.Z.; Humaidi, S.; Sembiring, T.; Sembiring, K.; Yuliarto, B. Review-A Pollutant Gas Sensor Based On $\mathrm{Fe}_{3} \mathrm{O}_{4}$ Nanostructures: A Review. J. Electrochem. Soc. 2021, 168, 027510. [CrossRef] 
22. Radoń, A.; Hawełek, Ł.; Łukowiec, D.; Kubacki, J.; Włodarczyk, P. Dielectric and electromagnetic interference shielding properties of high entropy ( $\mathrm{Zn}, \mathrm{Fe}, \mathrm{Ni}, \mathrm{Mg}, \mathrm{Cd}) \mathrm{Fe}_{2} \mathrm{O}_{4}$ ferrite. Sci. Rep. 2019, 9, 20078. [CrossRef]

23. Radon, A.; Łukowiec, D.; Włodarczyk, P. Microwave absorption by dextrin-magnetite nanocomposite in frequencies below $2.5 \mathrm{GHz}$ : Role of magnetite content, shape and temperature on magneto-dielectric properties. Mater. Des. 2020, $193,108860$. [CrossRef]

24. Debnath, S.; Das, R. Cobalt doping on nickel ferrite nanocrystals enhances the micro-structural and magnetic properties: Shows a correlation between them. J. Alloys Compd. 2021, 852, 156884. [CrossRef]

25. Nath, D.; Singh, F.; Das, R. X-ray diffraction analysis by Williamson-Hall, Halder-Wagner and size-strain plot methods of CdSe nanoparticles- a comparative study. Mater. Chem. Phys. 2020, 239, 122021. [CrossRef]

26. Yuan, K.; Lee, S.S.; Cha, W.; Ulvestad, A.; Kim, H.; Abdilla, B.; Sturchio, N.C.; Fenter, P. Oxidation induced strain and defects in magnetite crystals. Nat. Commun. 2019, 10, 703. [CrossRef]

27. Sneed, B.T.; Young, A.P.; Tsung, C.K. Building up strain in colloidal metal nanoparticle catalysts. Nanoscale 2015, 7, 12248-12265. [CrossRef]

28. Dheyab, M.A.; Aziz, A.A.; Jameel, M.S.; Noqta, O.A.; Khaniabadi, P.M.; Mehrdel, B. Simple rapid stabilization method through citric acid modification for magnetite nanoparticles. Sci. Rep. 2020, 10, 10793. [CrossRef] [PubMed]

29. Radon, A.; Drygała, A.; Hawełek, Ł.; Łukowiec, D. Structure and optical properties of $\mathrm{Fe}_{3} \mathrm{O}_{4}$ nanoparticles synthesized by co-precipitation method with different organic modifiers. Mater. Charact. 2017, 131, 148-156. [CrossRef]

30. Chernyshova, I.V.; Hochella, M.F.; Madden, A.S. Size-dependent structural transformations of hematite nanoparticles. 1. Phase transition. Phys. Chem. Chem. Phys. 2007, 9, 1736-1750. [CrossRef] [PubMed]

31. Shipilin, M.A.; Zakharova, I.N.; Shipilin, A.M.; Bachurin, V.I. Mössbauer studies of magnetite nanoparticles. J. Surf. Investig. X-ray Synchrotron Neutron Tech. 2014, 8, 557-561. [CrossRef]

32. Bonkerud, J.; Zimmermann, C.; Weiser, P.M.; Vines, L.; Monakhov, E.V. On the permittivity of titanium dioxide. Sci. Rep. 2021, 11, 12443. [CrossRef]

33. Woodward, W.H.H. Broadband Dielectric Spectroscopy-A Practical Guide. In ACS Symposium Series; American Chemical Society: Washington, DC, USA, 2021.

34. Kooti, M.; Sedeh, A.N.; Gheisari, K.; Figuerola, A. Synthesis, characterization, and performance of nanocomposites containing reduced graphene oxide, polyaniline, and cobalt ferrite. Phys. B Condens. Matter 2021, 612, 412974. [CrossRef]

35. Boonlakhorn, J.; Manyam, J.; Krongsuk, S.; Thongbai, P.; Srepusharawoot, P. Enhanced dielectric properties with a significantly reduced loss tangent in $\left(\mathrm{Mg}^{2+}, \mathrm{Al}^{3+}\right)$ co-doped $\mathrm{CaCu}_{3} \mathrm{Ti}_{4} \mathrm{O}_{12}$ ceramics: DFT and experimental investigations. RSC Adv. 2021, 11, 25038-25046. [CrossRef]

36. Hussain, M.; Khan, R.; Khan, T.Z.; Khan, G.; Khattak, S.; Rahman, M.U.; Ali, S.; Iqbal, Z.; Safeen, K. Dielectric and magnetic properties of cobalt doped $\gamma-\mathrm{Fe}_{2} \mathrm{O}_{3}$ nanoparticles. J. Mater. Sci. Mater. Electron. 2019, 30, 13698-13707. [CrossRef]

37. Türkay, S.; Tataroğlu, A. Complex dielectric permittivity, electric modulus and electrical conductivity analysis of Au/Si $\mathrm{N}_{4} / \mathrm{p}-$ GaAs (MOS) capacitor. J. Mater. Sci. Mater. Electron. 2021, 31, 11418-11425. [CrossRef]

38. Altındal, S.;; Ulusoy, M.; Özçelik, S.; Azizian-Kalandaragh, Y. On the frequency-dependent complex-dielectric, complex-electric modulus and conductivity in Au/(NiS:PVP)/n-Si structures. J. Mater. Sci. Mater. Electron. 2021, 32, 20071-20081. [CrossRef]

39. Megdiche, M.; Perrin-Pellegrino, C.; Gargouri, M. Conduction mechanism study by overlapping large-polaron tunnelling model in $\mathrm{SrNiP}_{2} \mathrm{O}_{7}$ ceramic compound. J. Alloys Compd. 2014, 584, 209-215. [CrossRef]

40. Jebli, M.; Rayssi, C.; Dhahri, J.; Ben Henda, M.; Belmabrouk, H.; Bajahzar, A. Structural and morphological studies, and temperature/frequency dependence of electrical conductivity of $\mathrm{Ba}_{0.9} 7 \mathrm{La}_{0.02} \mathrm{Ti}_{1-\mathrm{x}} \mathrm{Nb}_{4 \mathrm{x} / 5} \mathrm{O}_{3}$ perovskite ceramics. RSC Adv. 2021, 11, 23664-23678. [CrossRef]

41. Liu, H.; Di Valentin, C. Band Gap in Magnetite above Verwey Temperature Induced by Symmetry Breaking. J. Phys. Chem. C 2017, 121, 25736-25742. [CrossRef]

42. Cuenca, J.A.; Bugler, K.; Taylor, S.; Morgan, D.; Williams, P.; Bauer, J.; Porch, A. Study of the magnetite to maghemite transition using microwave permittivity and permeability measurements. J. Phys. Condens. Matter 2016, 28, 106002. [CrossRef] 